\title{
Comparative Analysis of DCF based Dispersion Compensation Techniques in Optical Fiber Communication Link using Different Input Transmitter Conditions at 10 Gbps
}

\author{
Gaurav Sharma ${ }^{a}$, Dr. Archana Agrawal ${ }^{\text {b }}$, Dr. Anurag Paliwal ${ }^{c}$ \\ ${ }^{\mathrm{a}, \mathrm{b}}$ Department of ECE, Sangam University, Bhilwara, India \\ ${ }^{c}$ Department of ECE, Geetanjali Institute of Technical Studies ,Udaipur, India \\ a gauravbhl.sharma@gmail.com, ${ }^{\mathrm{b}}$ archana.agrawal@ sangamuniversity.ac.in, ${ }^{\mathrm{c}}$ anurag.paliwal@ gits.ac.in
}

Article History: Received: 10 November 2020; Revised 12 January 2021 Accepted: 27 January 2021; Published online: 5 April 2021

\begin{abstract}
In this paper, Dispersion Compensating Fiber (DCF) based various dispersion compensating techniques (pre, post and symmetrical) with different modulation format like Non Return to Zero(NRZ), Return to Zero(RZ), Carrier Suppressed Return to Zero(CSRZ) and Duo Binary(DB) along with PN, FCC and Walsh code input sequences are implemented. Simulation and analysis of these implemented techniques were done at $10 \mathrm{Gbps}$ bit rate and input laser power ranging from 1 $\mathrm{mW}$ to $10 \mathrm{~mW}$ at transmission distance of $240 \mathrm{~km}$ using BER Analyzer in Optisystem 17.0 software. Comparison between different techniques was done in terms of Q factor and BER versus input CW laser power for different modulations and input sequences. From the analysis, it is concluded that when Walsh code as user defined input sequence are used for all the implementation, it gives higher value of Q factor and lower value of Bit Error Rate as compared to PN and FCC codes for most of the input $\mathrm{CW}$ laser power.
\end{abstract}

Keywords: DCF, NRZ, RZ, CSRZ, DB, BER, Q factor, CW Laser Power

\section{Introduction}

Optical Fiber Communication is one of the most important topics of research in today's world communication systems. Optical communication system like other system faces problems like dispersion, attenuation, and nonlinear effects that cause degradation in its performance. Among them, dispersion affects the system the most and it is difficult to overcome it as compared to the other two problems [1]. Dispersion is the main reason for the Inter Symbol Interference of the output pulse rendering them undetectable at the receiving side [2]. Due to ISI, the receiver may not be able to differentiate between 0 and 1 . Also, we cannot increase the data rate of the fiber optic communication link beyond a certain limit with the required accuracy. As a result, dispersion is a limiting factor on the data rate of fiber optic communication link [3].Thus in order to achieve high data rates, dispersion compensation is the most important feature in optical fiber communication links to compensate for the dispersion of optical pulses.

In this paper, the whole comparative analysis is based on the type of DCF based dispersion compensation techniques, types of modulation techniques and types of input sequence code used for the simulation.

\section{A. DCF based Dispersion Compensation Techniques}

In this technique a fiber having large negative dispersion coefficient is used along with a Single Mode Fiber (SMF) having positive. Therefore the overall dispersion of the fiber link is zero. The length of the DCF is shorter as compared to SMF. The placement of dispersion compensating fiber in the transmission plays an important role, which decides the signal quality at the receiver end [4].

In order to mitigate the dispersion effect three compensation techniques have been presented:

a. Pre-compensation: In Pre compensation scheme, Dispersion Compensation Fiber (DCF) is placed before the SMF to compensate the dispersion of the standard fiber.

b. Post-compensation: In Post compensation scheme, DCF is placed after SMF to mitigate the dispersion introduced.

c. Symmetrical-compensation: In Symmetrical compensation scheme, involves the placement of the DCF before and after the SMF to overcome the effect of dispersion [5-7].

In this paper, analysis has been done on all the three above DCF techniques. The length of the SMF was taken to be $100 \mathrm{~km}$ and dispersion coefficient of fiber was taken to be $17 \mathrm{ps} / \mathrm{nm}-\mathrm{km}$ whereas length of DCF was 
taken to be $20 \mathrm{~km}$ and dispersion coefficient was taken to be $-85 \mathrm{ps} / \mathrm{nm}-\mathrm{km}$. The loop control system has two loops in post and pre setup. In each loop $100 \mathrm{~km} \mathrm{SMF}$ and $20 \mathrm{~km} \mathrm{DCF}$ is used in order to compensate for the dispersion slope and accumulated dispersion in the fiber but in symmetrical setup has one loop only, so the of fiber length of the channel will remains to $240 \mathrm{~km}$.

\section{B. Modulation Techniques}

When analyzing the performance of optical communication systems, the data transmission format must be analyzed because it deals directly with the system output. Many coding techniques have been proposed before and have become standard in telecommunication and computer networks. Non-return to zero (NRZ) and Return to zero (RZ) are two very common modulation techniques, which are used to modulate optical pulses in optical networks [8].

Other schemes of modulation techniques were suggested such as carrier suppressed return to zero [9-11] and optical duo-binary [12-14]. In this paper different modulation formats like NRZ, RZ, CSRZ and Duo-Binary are used to analyze and compare between different dispersion compensation techniques.

\section{Input Sequence Code}

Basically PN Code sequences generated by Pseudo Random Bit Sequence generator are used to generate a digital sequence in optical fiber communication. In this paper, other two codes FCC and Walsh codes are used for the analysis. The FCC code can be designed by using tri diagonal matrix property, at any given number of users and weights. Walsh-Hadamard (WH) codes [15] are binary orthogonal and can easily be generated from Hadamard matrices. The orthogonal sequences generated from Hadamard matrices are called Walsh-Hadamard matrices [16], [17]. Orthogonality is that the most vital property of Hadamard-Walsh codes. Due to this orthogonality property, and when system is perfectly synchronized, the cross-correlation between any two WH codes of the same matrix (set) is zero.

\section{Simulation Setup}

We have used Optisystem 17.0 software to simulate our design. In the simulation setup at the transmitter side, CW laser is used as a source of light at the single frequency of $193.1 \mathrm{THz}$ with the power level ranging from 1 $\mathrm{mW}$ to $10 \mathrm{~mW}$. The digital sequence is generated by both pseudo random and user defined bit sequence generator at the transmission rate of $10 \mathrm{Gbps}$. To convert a digital sequence into electrical pulse different modulation format like Non Return to Zero (NRZ), Return to Zero (RZ), Carrier Suppressed Return to Zero (CSRZ), and Duo-Binary (DB) are used. Mach-Zehnder (MZ) modulator is used for the modulation of the optical signals whose another input is fed from the laser diode causes an optical modulation before entering into the medium. The medium includes optical fibers, DCF and optical amplifiers. Optical amplifiers are inserted after each fiber and DCF components for the compensation of attenuation. A PIN detector is used along with low pass Bessel filter is used at receiving end of the link to detect the optical pulses and convert it to the electrical signals. This electrical signal is applied to the BER analyzer through $3 \mathrm{R}$ generator to analyze the different fiber parameters.

Different simulation parameters of single channel optical system and fiber are tabulated in Table I and II respectively.

TABLE I. SINGLE CHANNELOPTICAL SYSTEM PARAMETERS

\begin{tabular}{|l|l|}
\hline \multicolumn{1}{|c|}{ Parameters } & \multicolumn{1}{|c|}{ VAluE } \\
\hline Bit Rate( Gb/s) & 10 \\
\hline Sequence Length & 1024 \\
\hline Samples/bit & 32 \\
\hline Sample Rate (Hz) & $3.2 \mathrm{e}+011$ \\
\hline Number of Samples & 32768 \\
\hline CW Laser frequency (THz) & 193.1 \\
\hline CW Laser Power (mW) & 1 to 10 \\
\hline Reference Wavelength (nm) & 1550 \\
\hline
\end{tabular}

TABLE II. FIBER PARAMETERS

\begin{tabular}{|c|c|c|}
\hline PARAMETERS & SMF & DCF \\
\hline
\end{tabular}




\begin{tabular}{|c|c|c|}
\hline Length(KM) & 100 & 20 \\
\hline $\begin{array}{c}\text { Dispersion(ps/nm } \\
/ \mathrm{km})\end{array}$ & 17 & -85 \\
\hline Dispersion Slope & 0.075 & -0.3 \\
\hline Attenuation & 0.2 & 0.6 \\
\hline $\begin{array}{c}\text { Differential } \\
\text { Group Delay(ps/nm) }\end{array}$ & 0.5 & 0.5 \\
\hline
\end{tabular}

In this setup, three DCF based dispersion compensation techniques using three different types of input sequences and four different modulations with different $\mathrm{CW}$ laser power are implemented. Fig. 1, 2 and 3 shows the simulation setup for the Pre, Post and Symmetrical DCF techniques for NRZ, RZ, CSRZ and Duo-Binary modulations using PN code generated by PRBS generator.

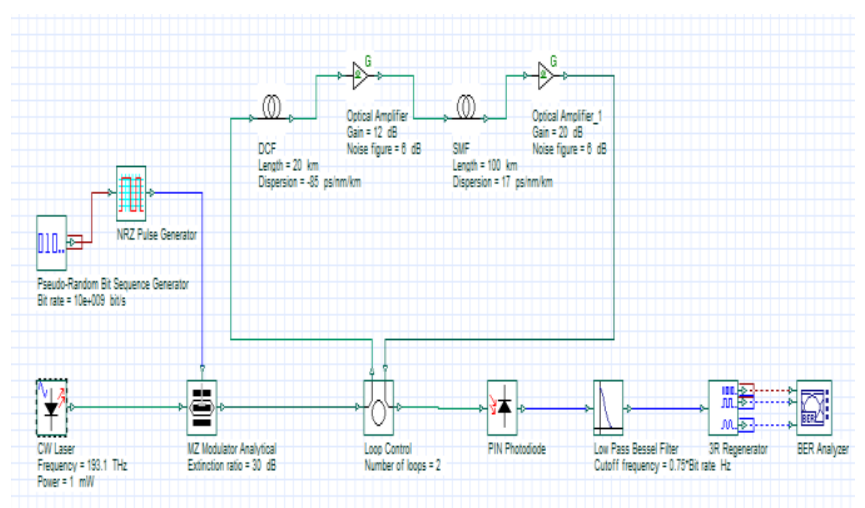

(a) Using NRZ modulation

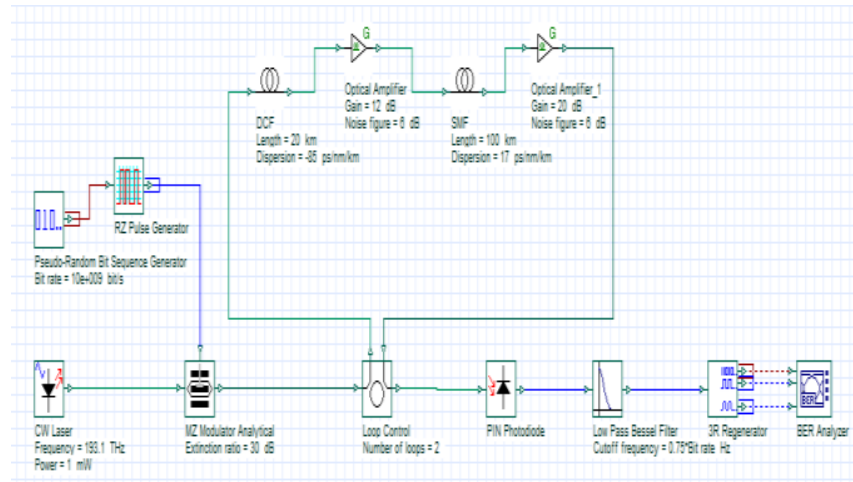

(b) Using RZ modulation

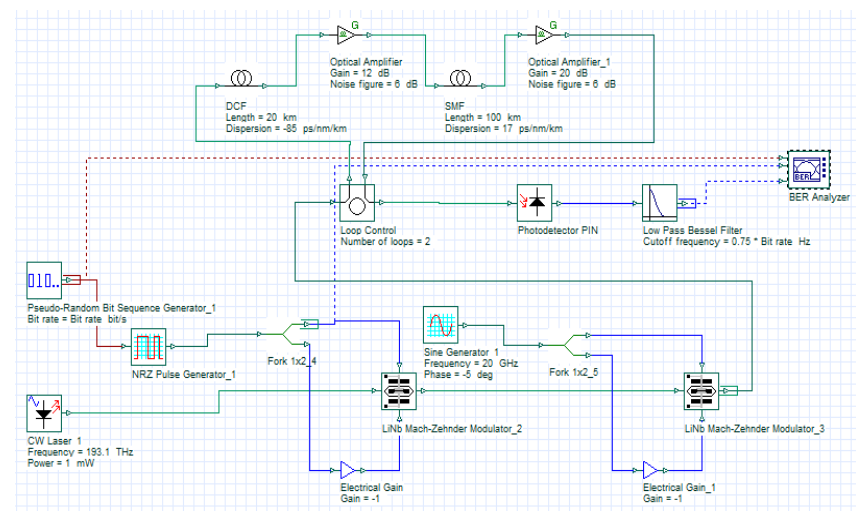

(c) Using CSRZ modulation 


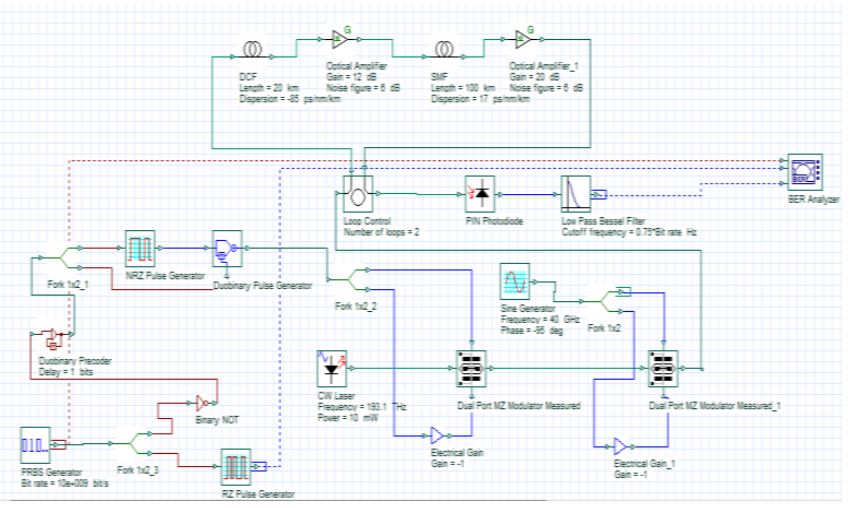

(d) Using Duo-Binary modulation

Fig. 1 Simulation setup for Pre DCF compensation using (a) NRZ (b) RZ (c) CSRZ and (d) Duo-Binary modulation.

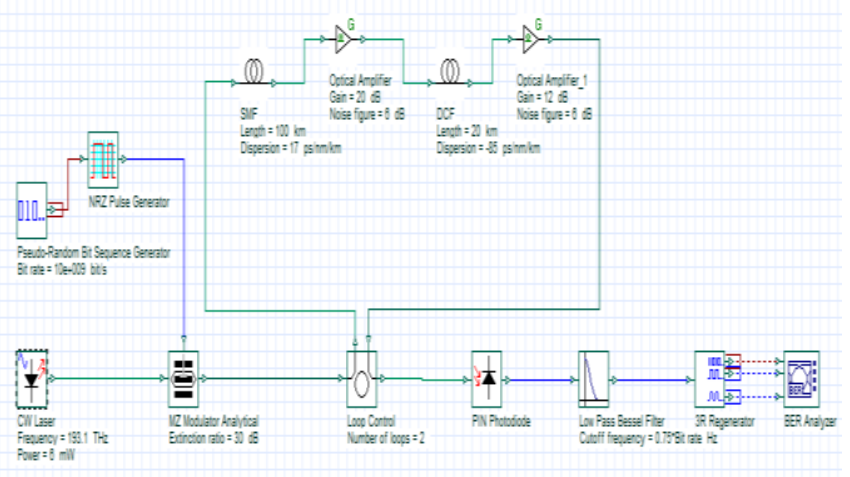

(a) Using NRZ modulation

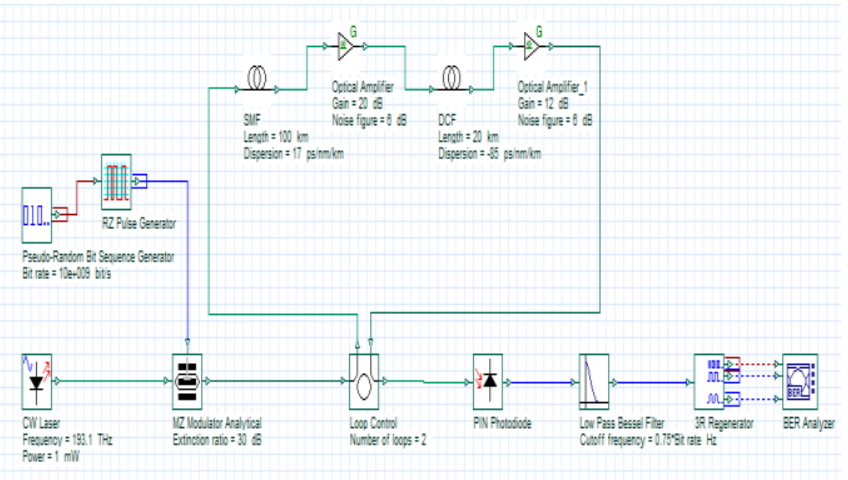

(b) Using RZ modulation

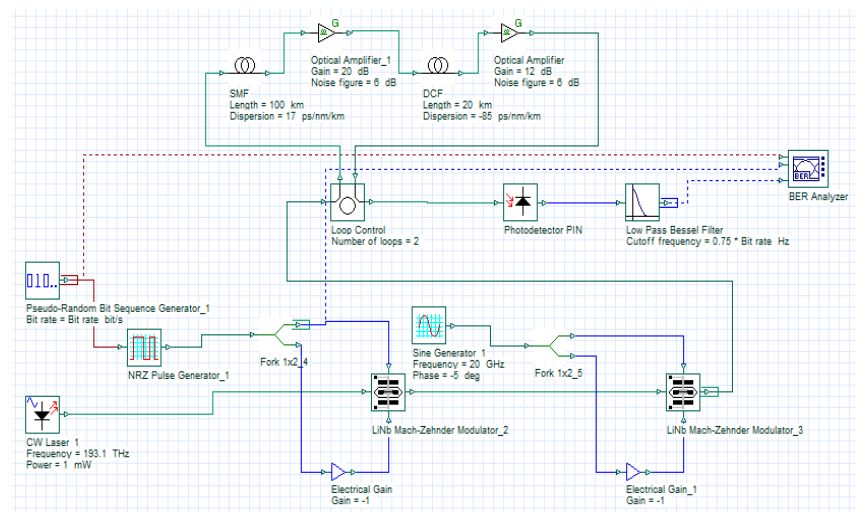


(c) Using CSRZ modulation

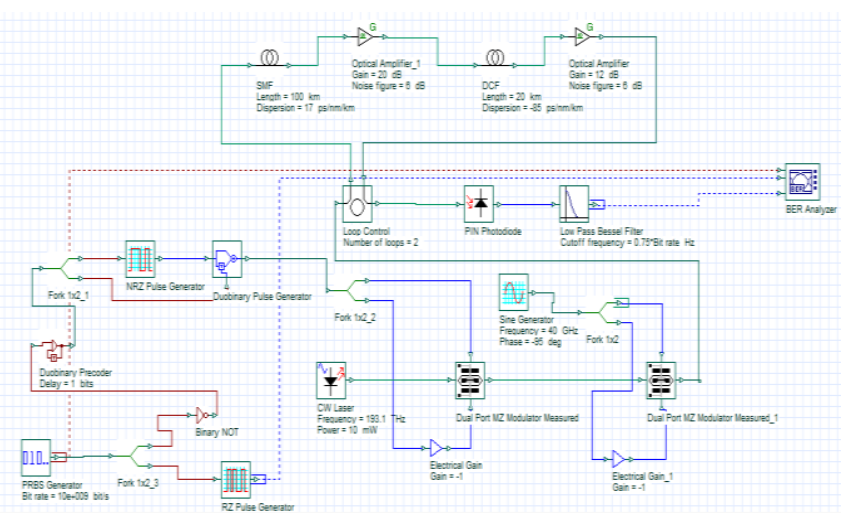

(d) Using Duo-Binary modulation

Fig. 2 Simulation setup for Post DCF compensation using (a) NRZ (b) RZ (c) CSRZ and (d) Duo-Binary modulation.

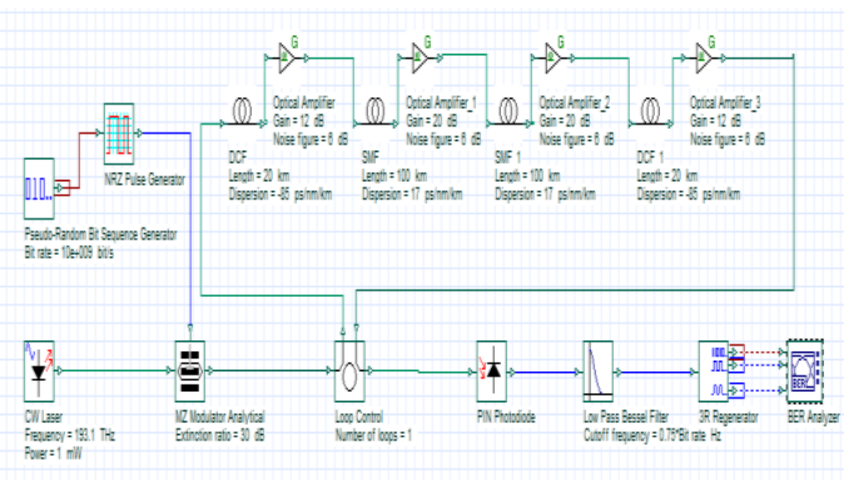

(a) Using NRZ modulation

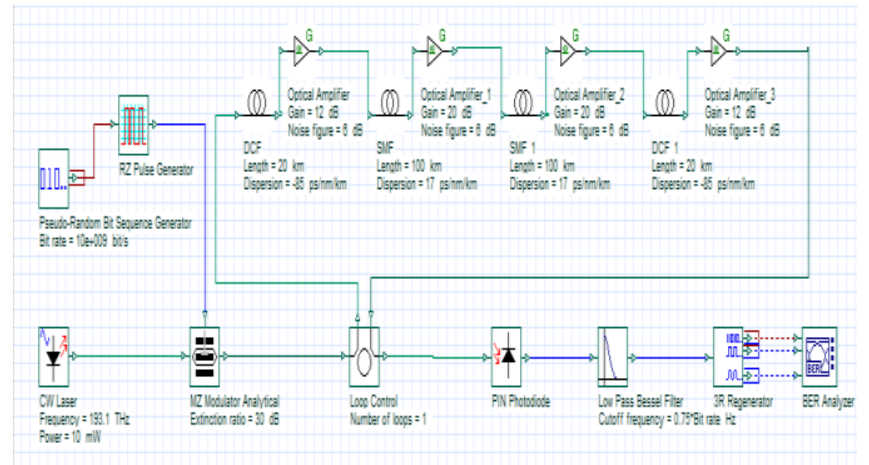

(b) Using RZ modulation

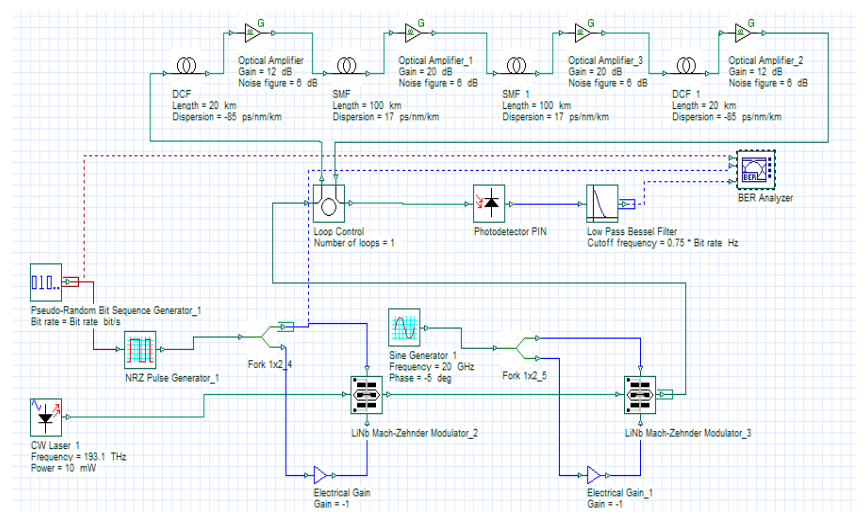


(c) Using CSRZ modulation

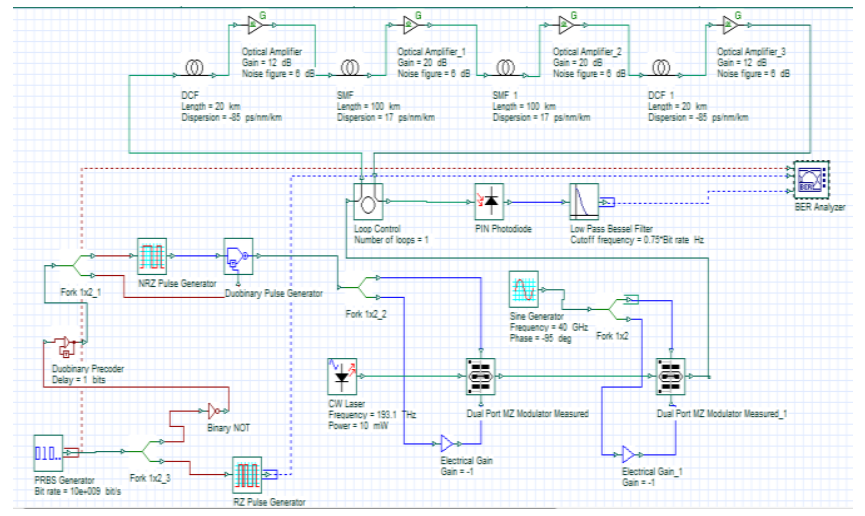

(d) Using Duo-Binary modulation

Fig. 3 Simulation setup for Symmetrical DCF compensation using (a) NRZ (b) RZ (c) CSRZ and (d) Duo-Binary modulation.

For the next simulation setup to apply FCC and Walsh code, PRBS generator is replaced by the user defined bit sequence generator in the entire Fig, where 16 bits of FCC Codes (0110111001010001) and Walsh codes (0110011001100110) are used for the simulation.

\section{Simulation Results}

All the simulated designs have been analyzed at $10 \mathrm{Gbps}$ in terms of Q factor and BER using BER analyzer in Optisystem 17.0 software and comparison between them was done on the basis of input sequences like PN, FCC and Walsh code, modulation formats (NRZ, RZ, CSRZ and Duo Binary) with CW laser power level from $1 \mathrm{~mW}$ to $10 \mathrm{~mW}$.

\section{A. Q factor versus Transmitted Power}

Fig. 4 shows the comparative analysis between Q factor and CW laser power ranges from $1 \mathrm{~mW}$ to $10 \mathrm{~mW}$ for the Pre, Post and Symmetrical DCF compensation technique using NRZ modulation. It provides the high value of $\mathrm{Q}$ factor $=50.2574$ at $8 \mathrm{~mW}$ for Pre DCF, Q factor=50.5778 at $9 \mathrm{~mW}$ for Post DCF and Q factor=61.863 for Symmetrical DCF technique using Walsh code.

Fig. 5 shows the comparison graph for the Pre, Post and Symmetrical DCF compensation technique using RZ modulation. It provides the high value of Q factor = 53.9792 for Pre DCF, Q factor=55.3907 for Post DCF and Q factor=52.4185 for Symmetrical DCF technique using Walsh code at $10 \mathrm{~mW} \mathrm{CW}$ laser power.

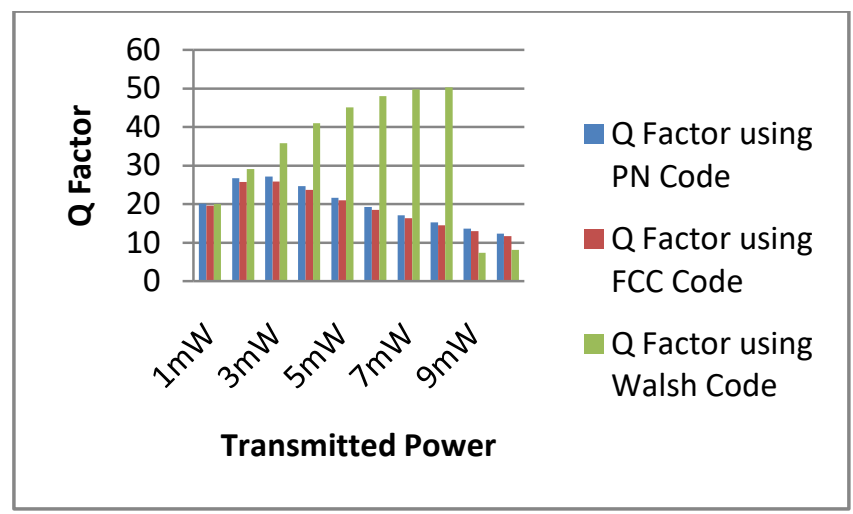

(a) Pre DCF Compensation 


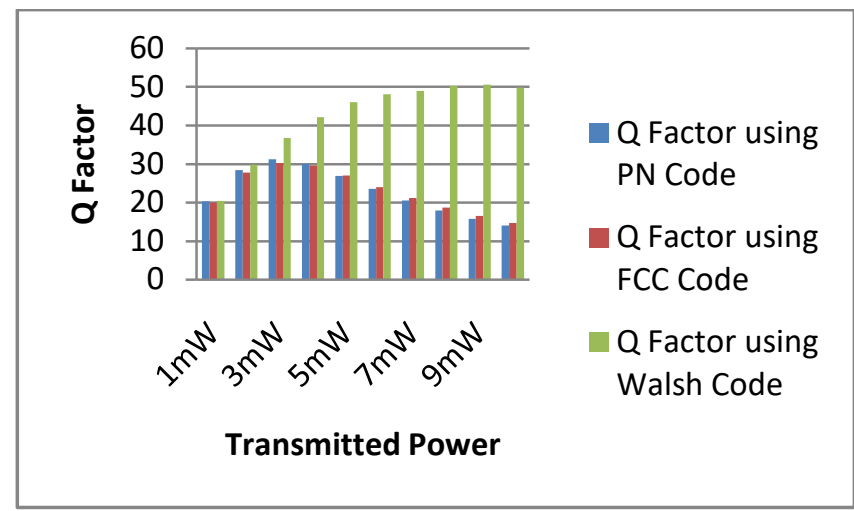

(b) Post DCF Compensation

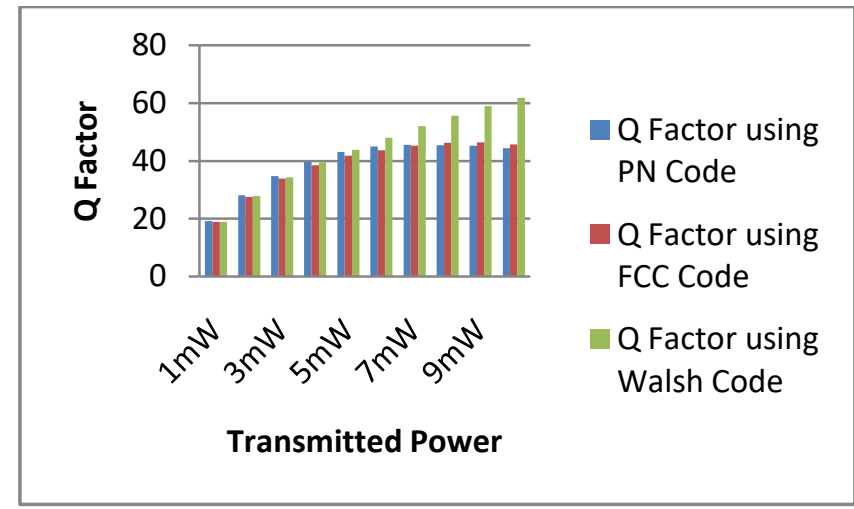

(c) Symmetrical DCF Compensation

Fig. 4 Q factor versus Transmitted Power for (a) Pre (b) Post and (c) Symmetrical DCF compensation technique using NRZ modulation

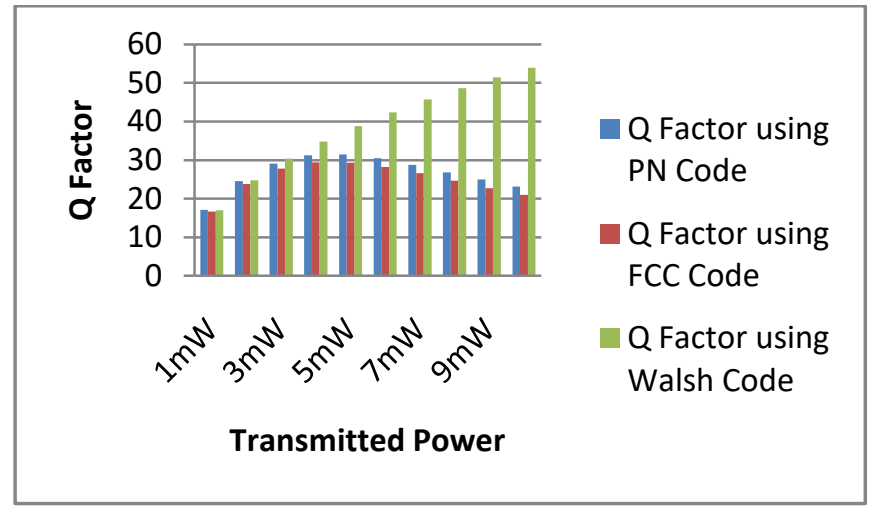

(a) Pre DCF Compensation

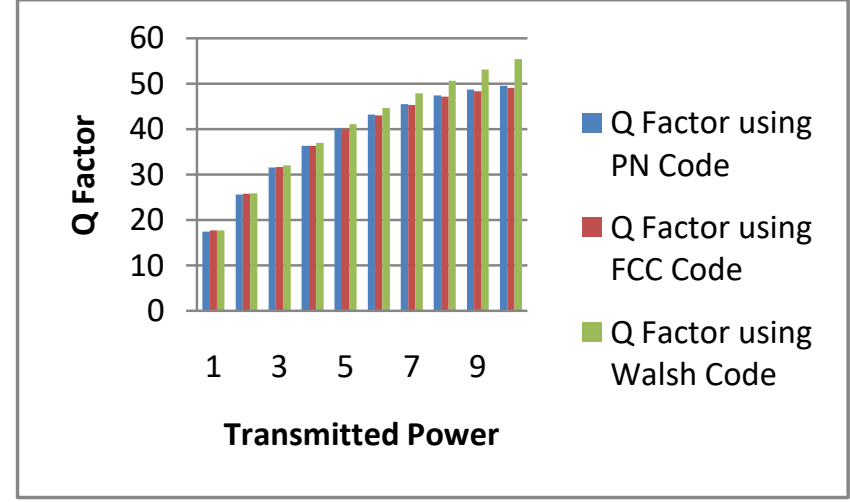

(b) Post DCF Compensation 


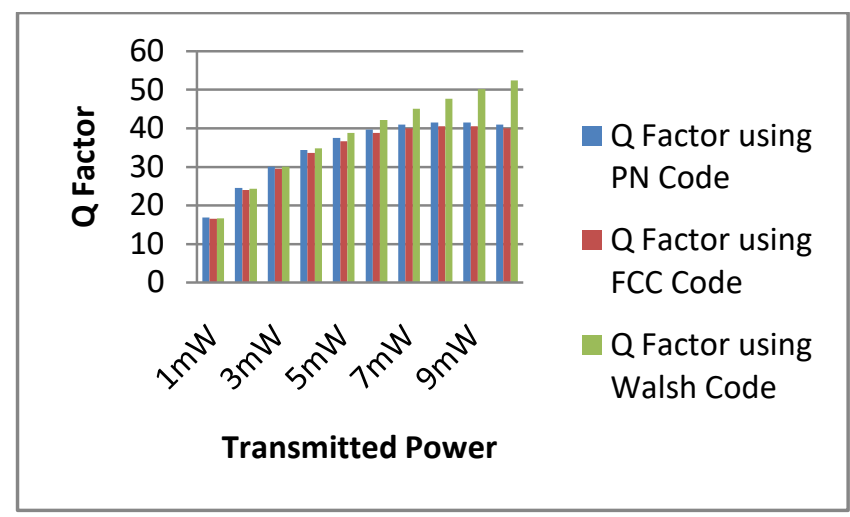

(c) Symmetrical DCF Compensation

Fig. 5 Q factor versus Transmitted Power for (a) Pre (b) Post and (c) Symmetrical DCF compensation technique using RZ modulation

Fig. 6 shows the comparative graph for the Pre, Post and Symmetrical DCF compensation technique using CSRZ modulation. It provides the high value of $\mathrm{Q}$ factor $=48.7397$ for Pre DCF, $\mathrm{Q}$ factor $=51.3228$ for Post DCF and Q factor=51.9043 for Symmetrical DCF technique using Walsh code at $10 \mathrm{~mW}$ CW laser power.

Fig. 7 shows the comparison graph for the Pre, Post and Symmetrical DCF compensation technique using CSRZ modulation. It provides the high value of $\mathrm{Q}$ factor $=44.0233$ for Pre DCF, $\mathrm{Q}$ factor $=47.4019$ for Post DCF and Q factor=44.8085 for Symmetrical DCF technique using Walsh code at $10 \mathrm{~mW}$ CW laser power.

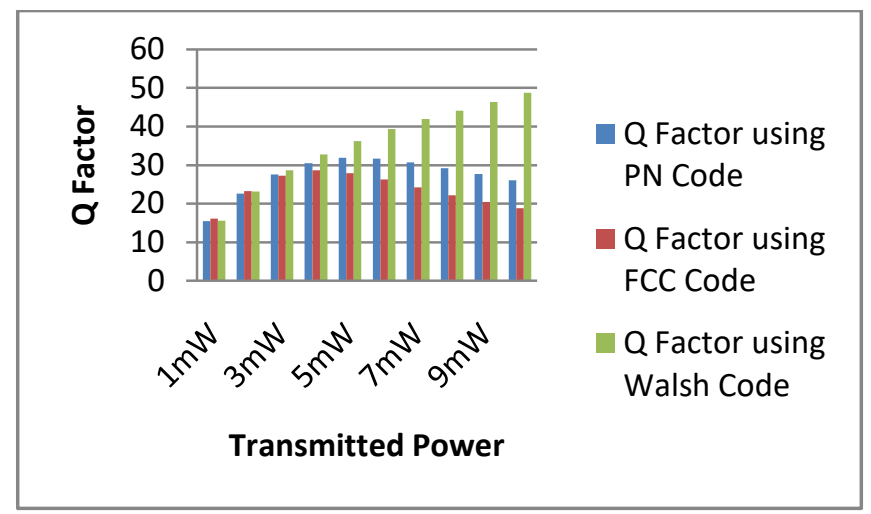

(a) Pre DCF Compensation

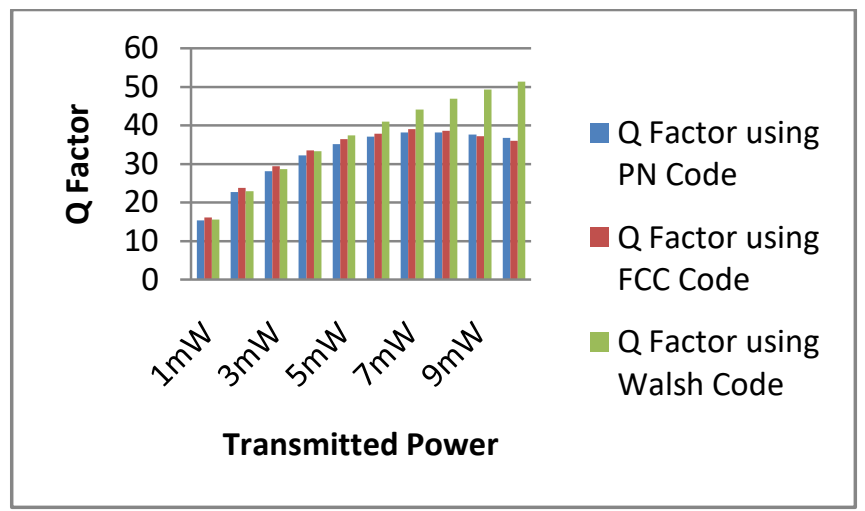

(b) Post DCF Compensation 


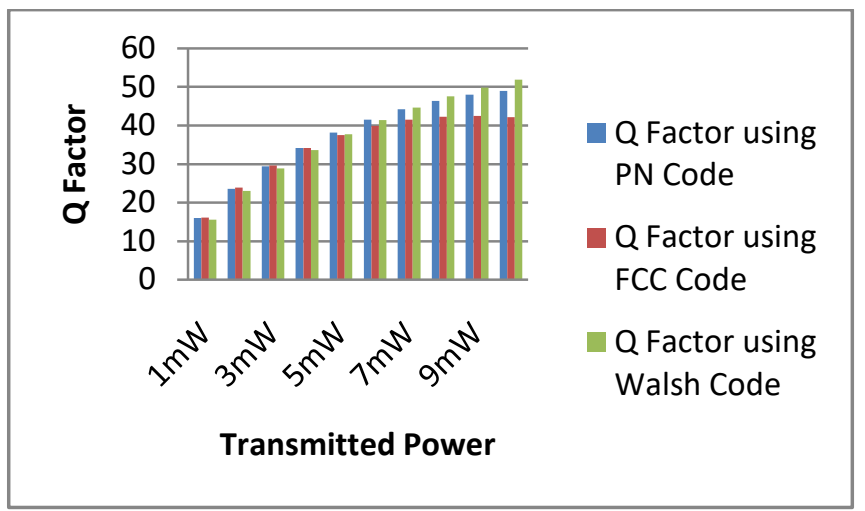

(c) Symmetrical DCF Compensation

Fig. 6 Q factor versus Transmitted Power for (a) Pre (b) Post and (c) Symmetrical DCF compensation technique using CSRZ modulation

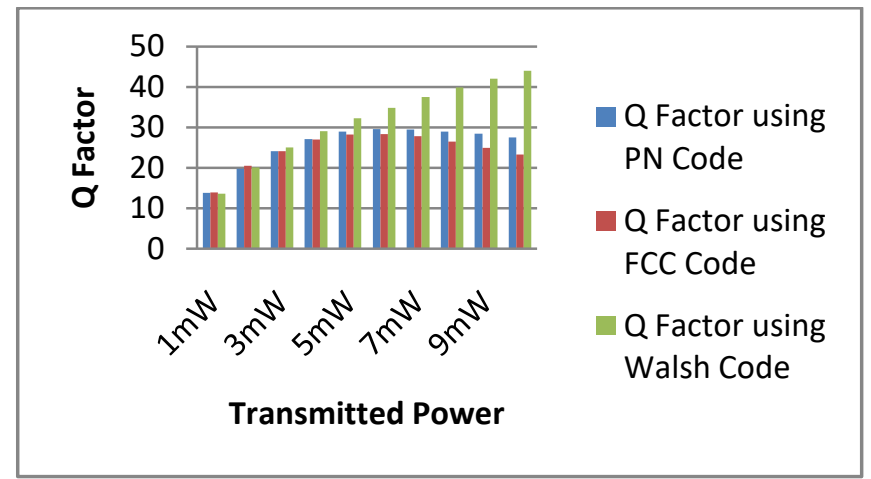

(a) Pre DCF Compensation

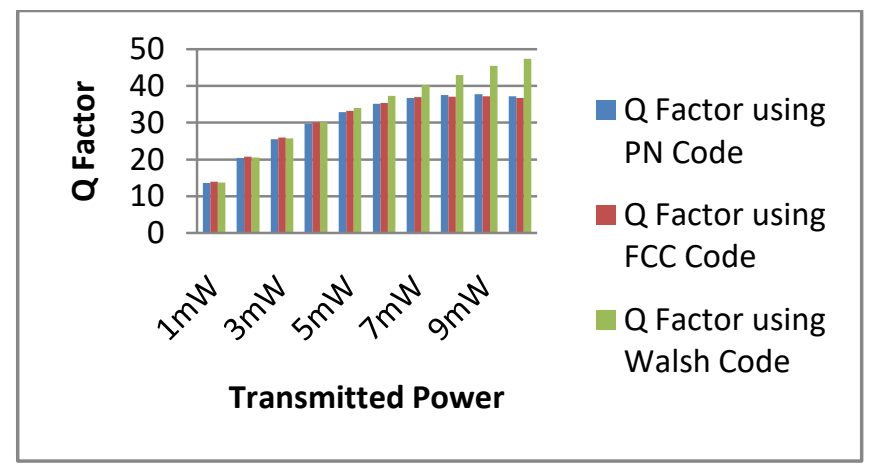

(b) Post DCF Compensation

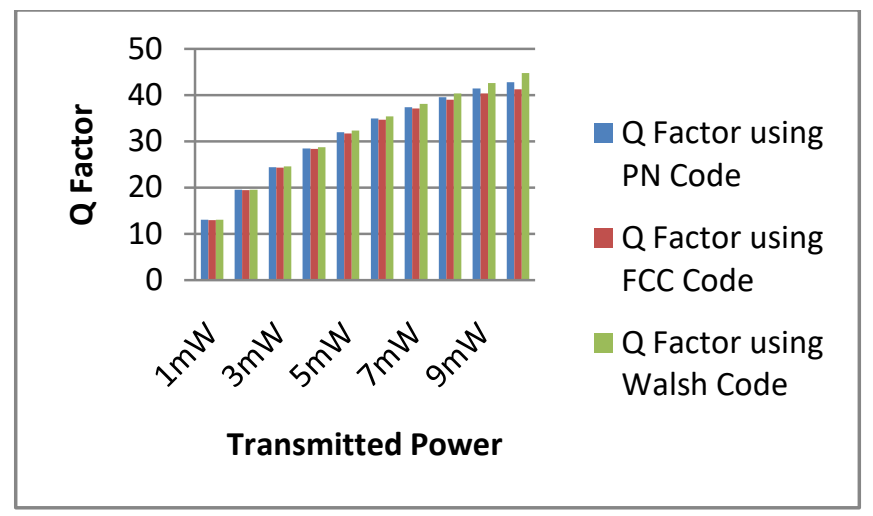

(c) Symmetrical DCF Compensation

Fig. 7 Q factor versus Transmitted Power for (a) Pre (b) Post and (c) Symmetrical DCF compensation technique using Duo-Binary modulation 


\section{B. BER versus Transmitted Power}

Fig. 8, 9,10 and 11 shows the comparative analysis between Bit Error Rate (BER) and transmitted CW laser power for the Pre, Post and Symmetrical DCF techniques using NRZ, RZ, CSRZ and Duo-Binary Modulation using PN, FCC and Walsh codes. From the graphs it is concluded that we get BER=0 using Walsh code for all the implemented techniques at $10 \mathrm{~mW} \mathrm{CW}$ laser power.

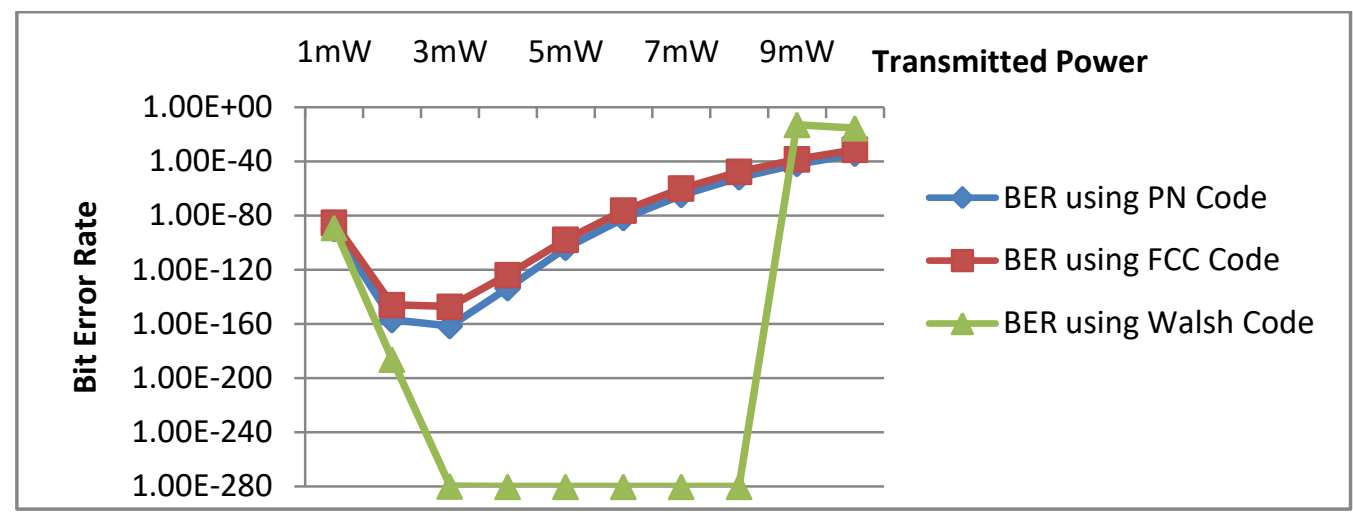

(a) Pre DCF Compensation

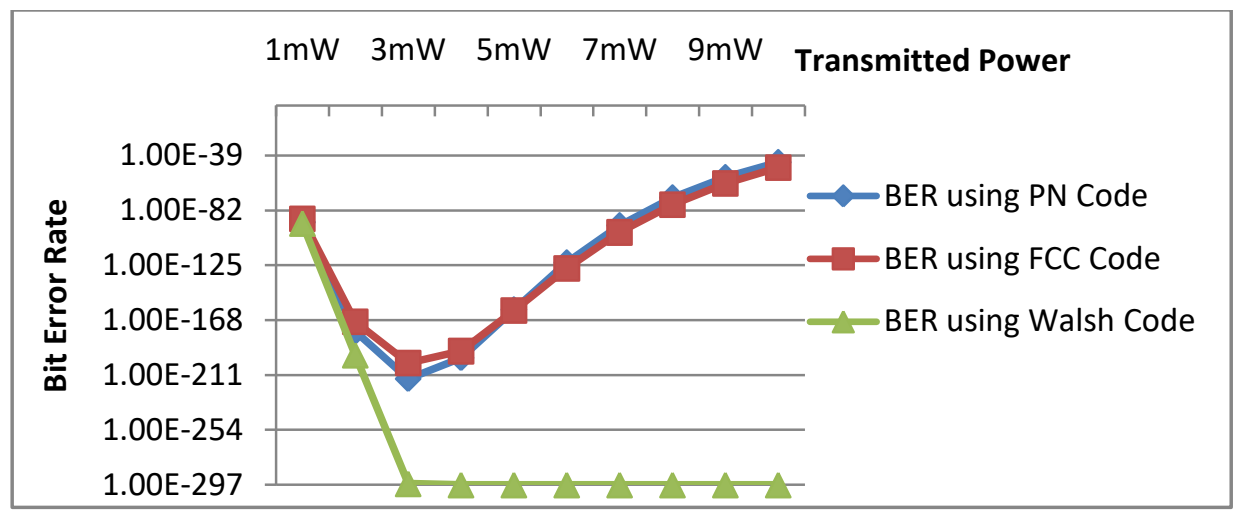

(b) Post DCF Compensation

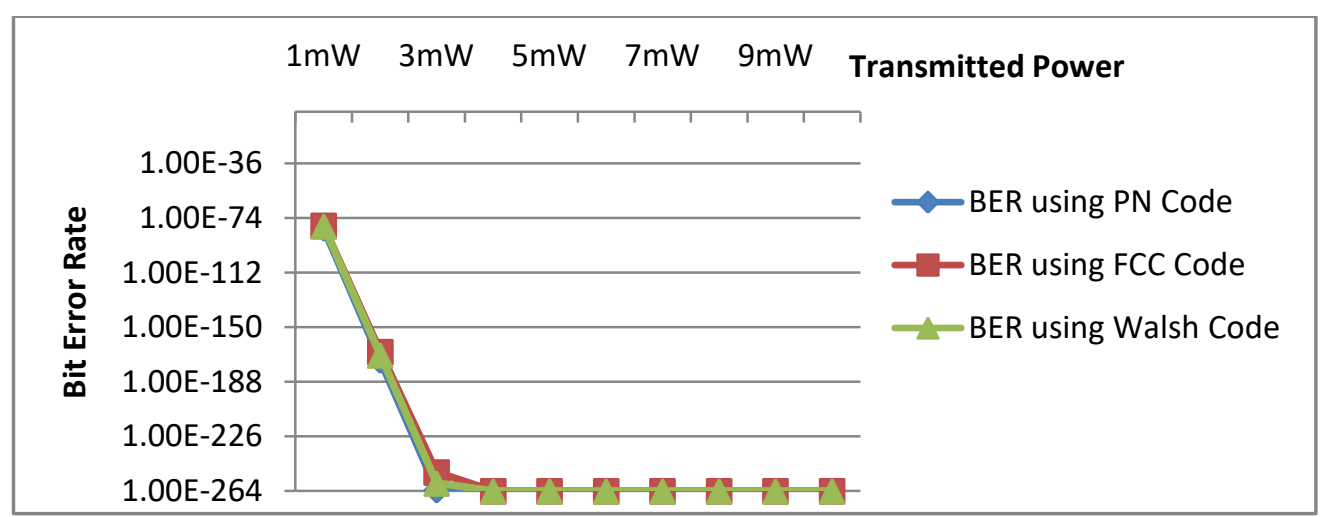

(c) Symmetrical DCF Compensation

Fig. 8 BER versus Transmitted Power for (a) Pre (b) Post and (c) Symmetrical DCF compensation technique using NRZ modulation 


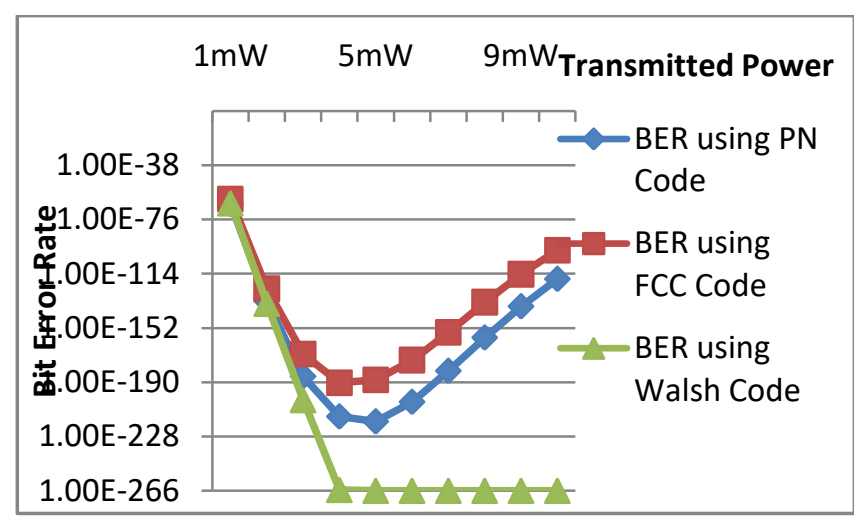

(a) Pre DCF Compensation

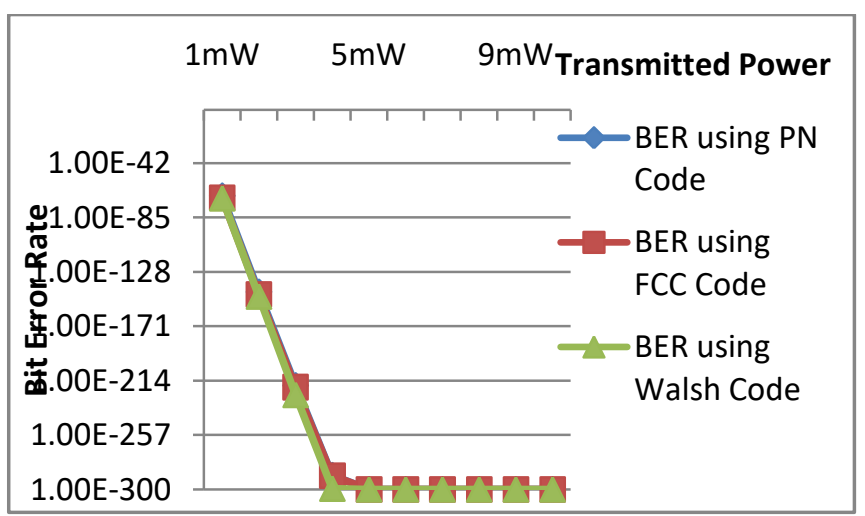

(b) Post DCF Compensation

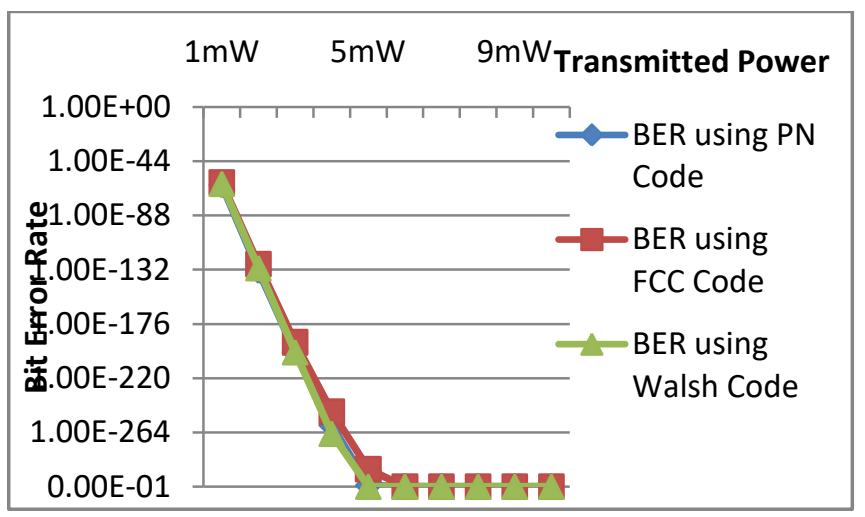

(c) Symmetrical DCF Compensation

Fig. 9 BER versus Transmitted Power for (a) Pre (b) Post and (c) Symmetrical DCF compensation technique using RZ modulation

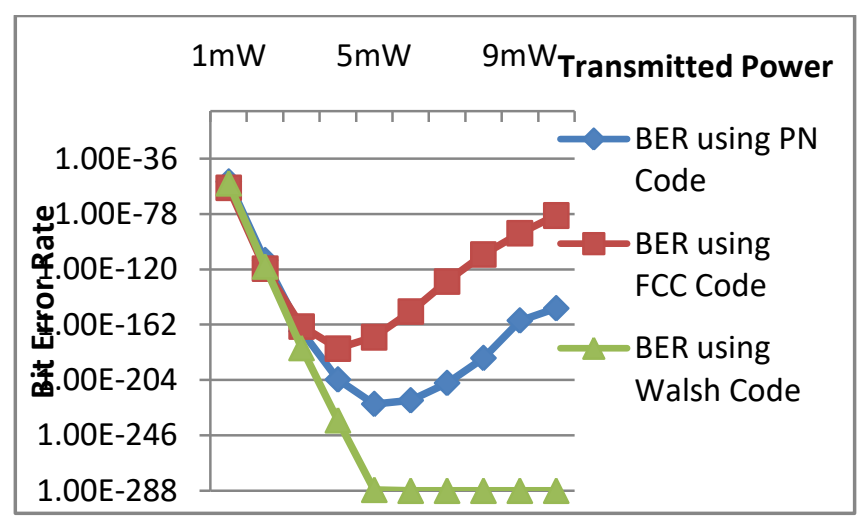


(a) Pre DCF Compensation

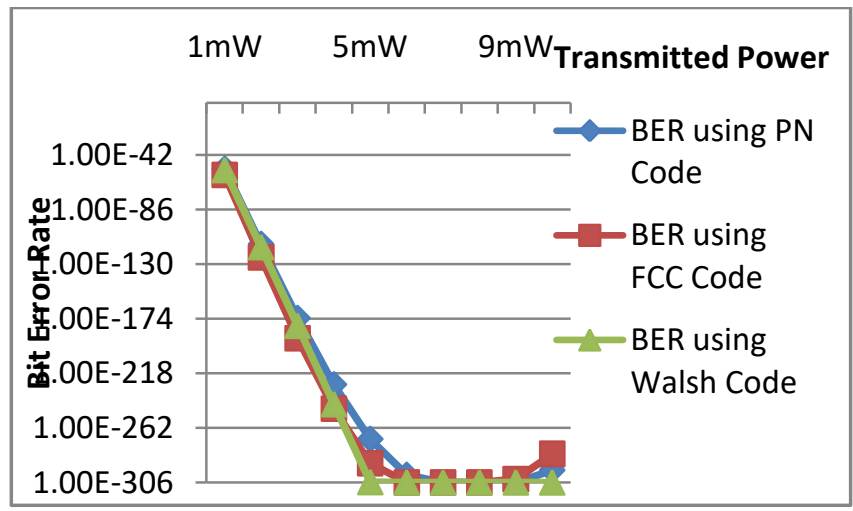

(b) Post DCF Compensation

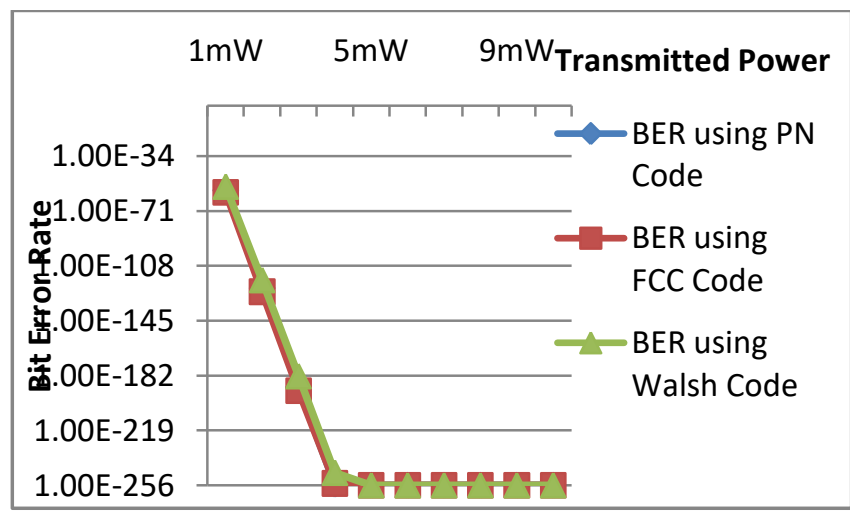

(c) Symmetrical DCF Compensation

Fig. 10 BER versus Transmitted Power for (a) Pre (b) Post and (c) Symmetrical DCF compensation technique using CSRZ modulation

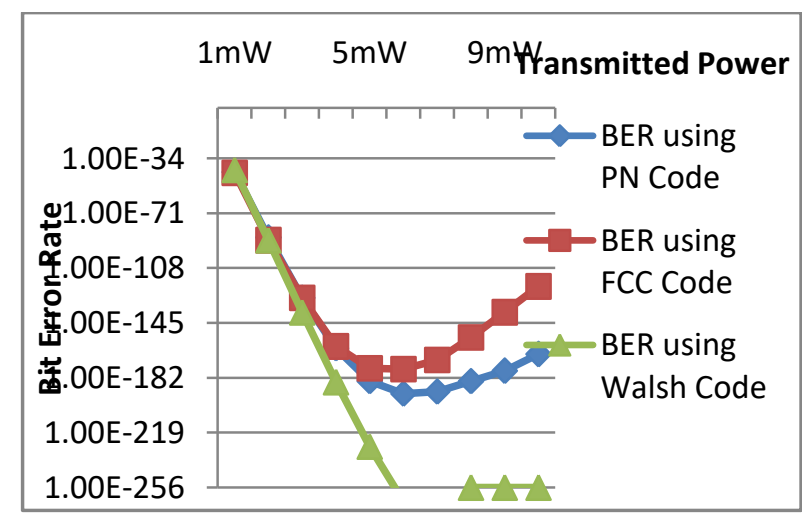

(a) Pre DCF Compensation

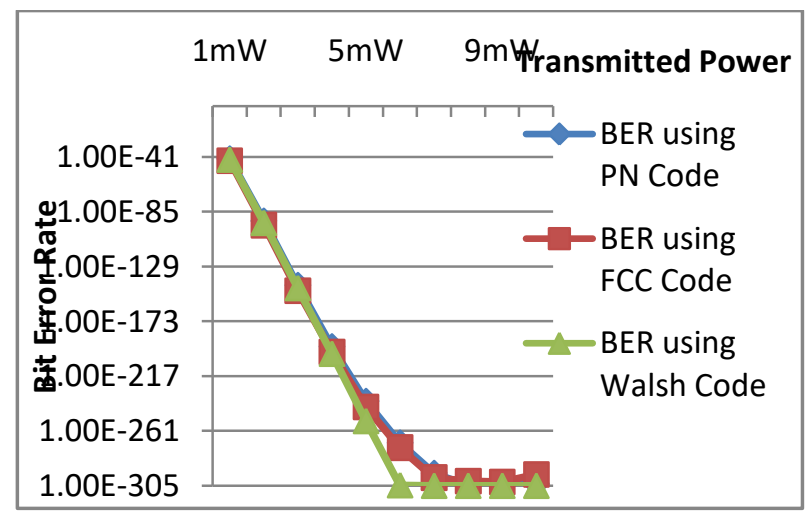




\section{(b) Post DCF Compensation}

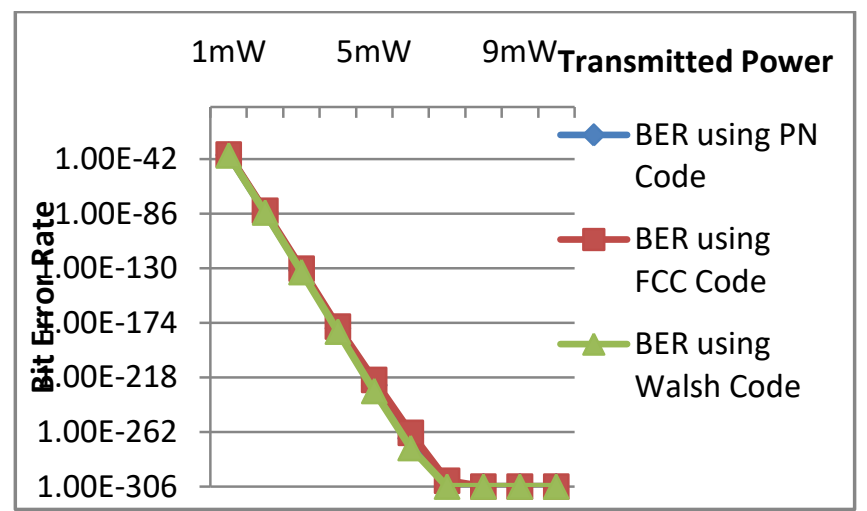

(c) Symmetrical DCF Compensation

Fig. 11 BER versus Transmitted Power for (a) Pre (b) Post and (c) Symmetrical DCF compensation technique using Duo-Binary modulation

\section{BER Diagram}

Fig.12, 13, 14, and 15 shows the Eye diagram or BER diagram for Pre, Post and Symmetrical DCF techniques using NRZ, RZ, CSRZ and Duo- Binary Modulation for only those value of CW laser power and Input sequence code in which we are getting the higher value of $Q$ factor and minimum value of BER.

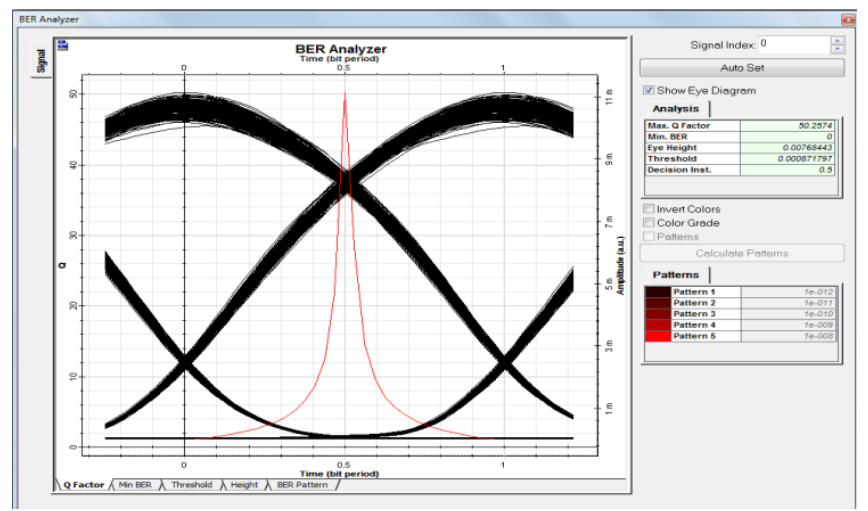

(a) Qfactor= 50.2574 and BER=0 at $8 \mathrm{mw}$

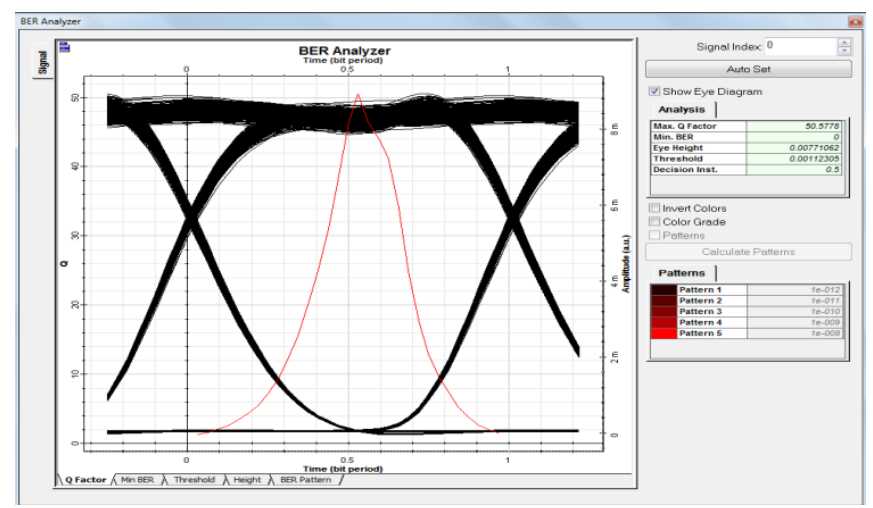

(b) Qfactor= 50.5778 and $\mathrm{BER}=0$ at $9 \mathrm{mw}$ 


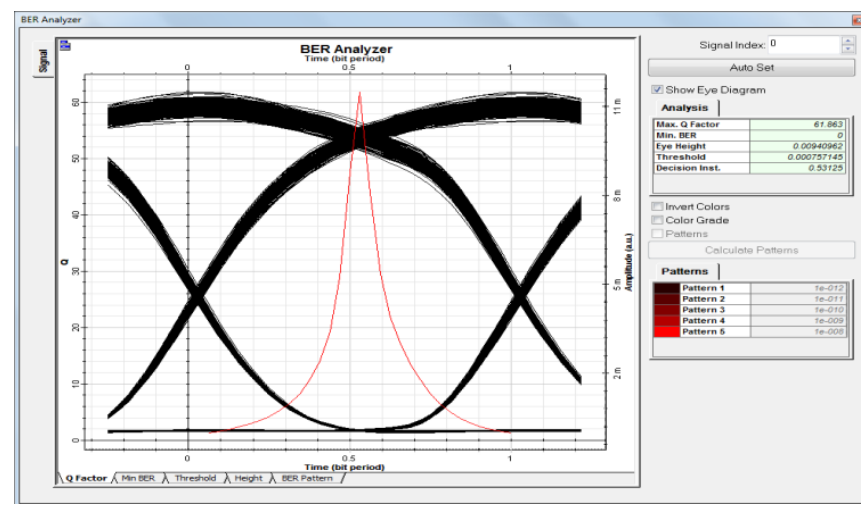

(c) Qfactor $=61.863$ and $\mathrm{BER}=0$ at $10 \mathrm{mw}$

Fig. 12 BER analyzer diagram for (a) Pre (b) Post and (c) Symmetrical DCF compensation technique using NRZ modulation for Walsh code

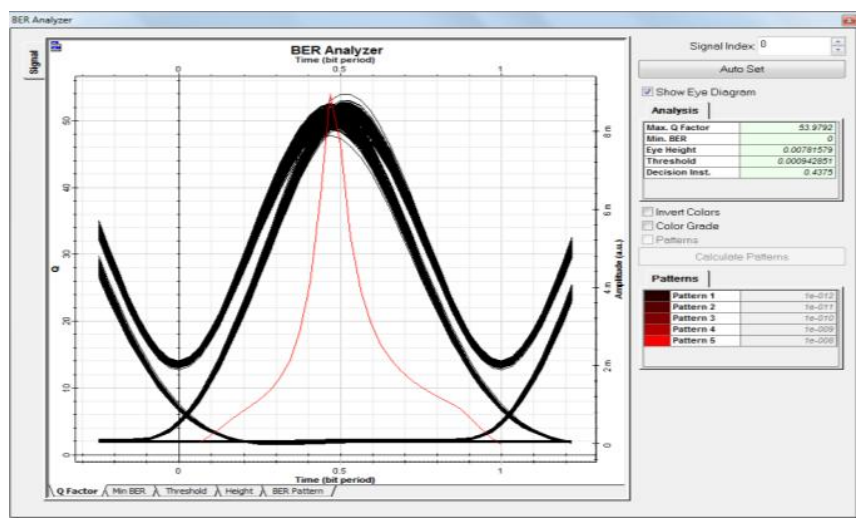

(a) Q factor= 53.9792 and $\mathrm{BER}=0$ at $10 \mathrm{~mW}$

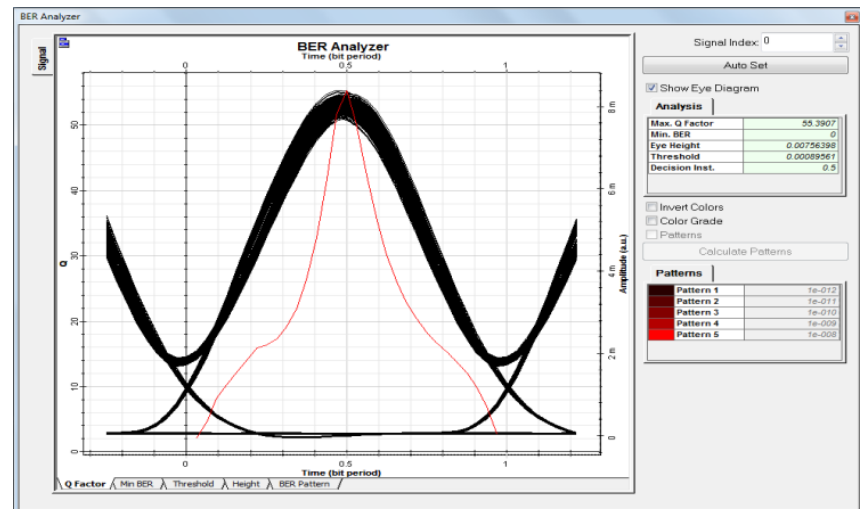

(b) Q factor= 55.3907 and $\mathrm{BER}=0$ at $10 \mathrm{~mW}$

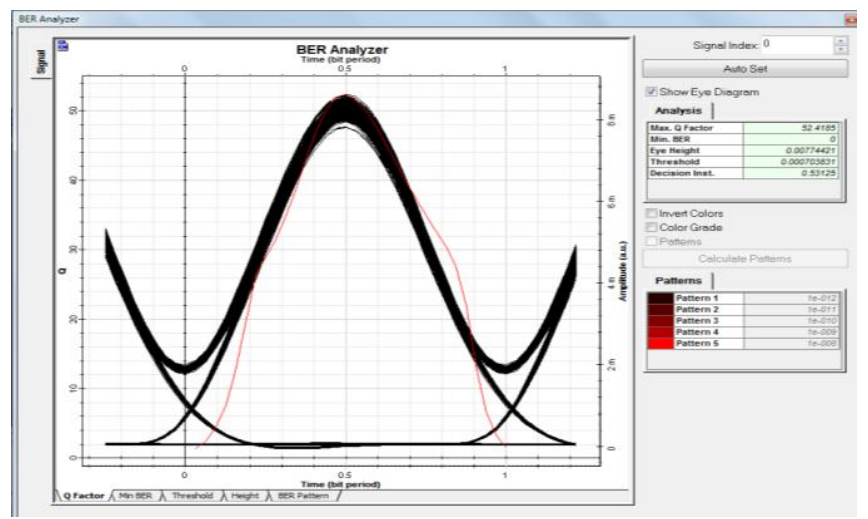


(c) Q factor= 52.4185 and $\mathrm{BER}=0$ at $10 \mathrm{~mW}$

Fig. 13 BER analyzer diagram for (a) Pre (b) Post and (c) Symmetrical DCF compensation technique using RZ modulation for Walsh code

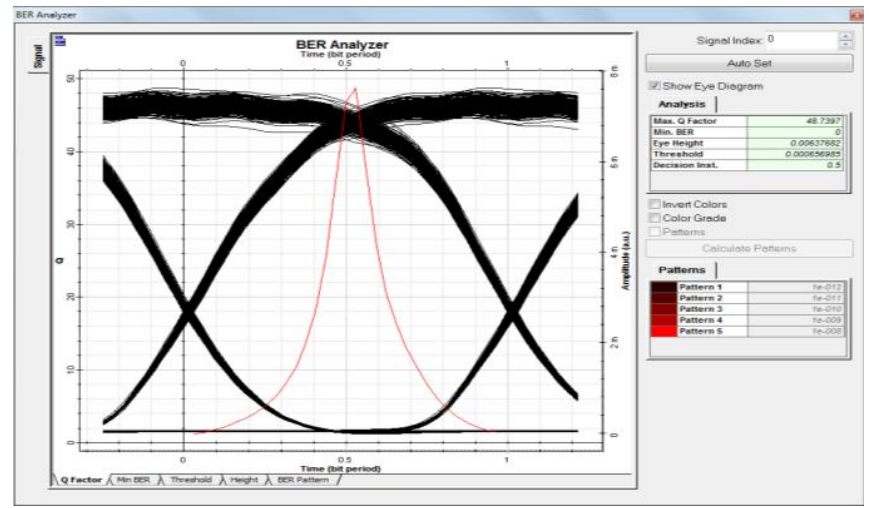

(a) Q factor $=48.7397$ and $\mathrm{BER}=0$ at $10 \mathrm{~mW}$

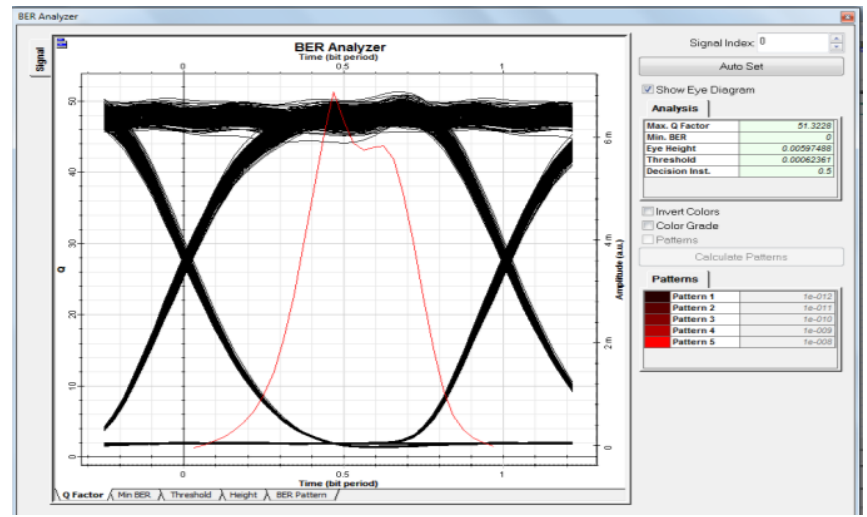

(b) $\mathrm{Q}$ factor $=51.3228$ and $\mathrm{BER}=0$ at $10 \mathrm{~mW}$

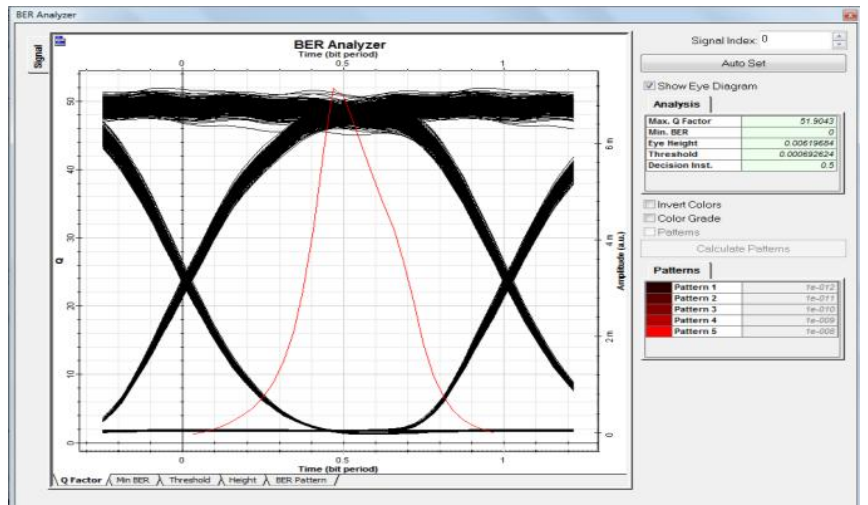

(c) Q factor= 51.9043 and $\mathrm{BER}=0$ at $10 \mathrm{~mW}$

Fig. 14 BER analyzer diagram for (a) Pre (b) Post and (c) Symmetrical DCF compensation technique using CSRZ modulation for Walsh code 


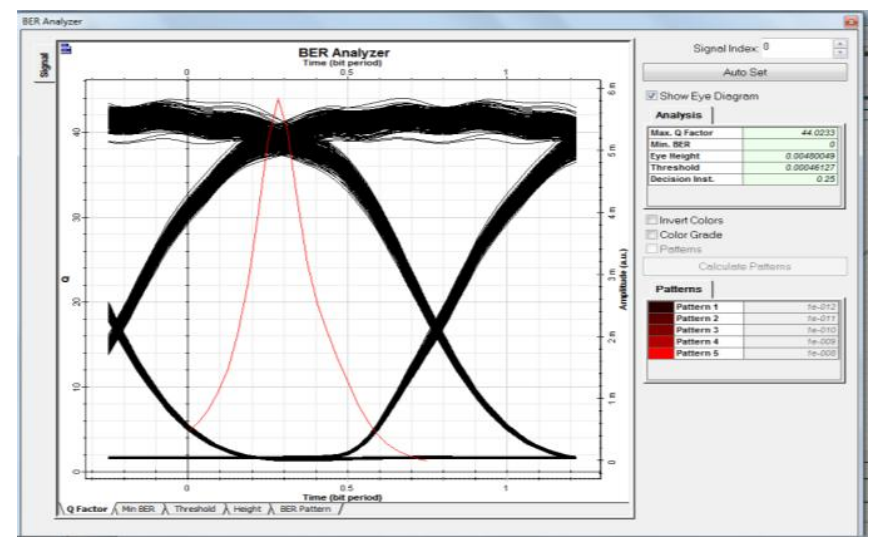

(a) $\mathrm{Q}$ factor $=44.0233$ and $\mathrm{BER}=0$ at $10 \mathrm{~mW}$

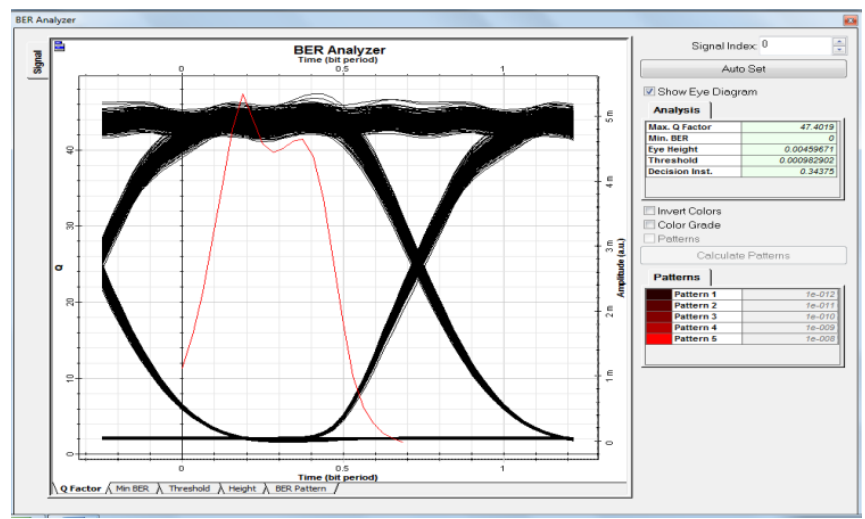

(b) $\mathrm{Q}$ factor $=47.4019$ and $\mathrm{BER}=0$ at $10 \mathrm{~mW}$

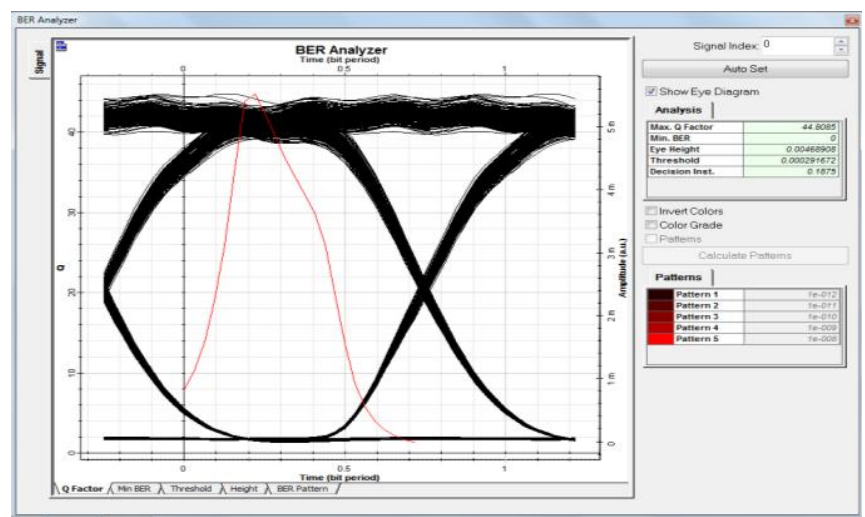

(a) $\mathrm{Q}$ factor $=44.8085$ and $\mathrm{BER}=0$ at $10 \mathrm{~mW}$

Fig. 15 BER analyzer diagram for (a) Pre (b) Post and (c) Symmetrical DCF compensation technique using DuoBinary modulation for Walsh code

\section{CONCLUSION AND FUTURE SCOPE}

The Inter Symbol Interference is decreased with the increment of Q factor and decrement of BER. BER is the function of system quality factor Q. In this paper we have done the comparative analysis for different DCF based dispersion compensation techniques using different modulation formats, input code sequences and input CW laser power to find out the efficient dispersion compensation techniques at 10 Gbps data rate and channel length of 240 $\mathrm{km}$. From the paper it is concluded that when Walsh code are used as input data sequence it gives the higher value of Q factor and minimum value of BER in almost all simulations as compared to PN and FCC codes used. In the future work, we will use this methodology for other dispersion compensation technique also for further comparative analysis to find out the efficient dispersion compensation techniques. 


\section{References}

N. K. Kahlon and G. Kaur," Various Dispersion Compensation Techniques for Optical System: A Survey”, Open Journal of Communications And Software Volume 1, Number 1, MAY 2014.

G. Keiser, Optical fiber communications. Wiley India, 2011.

G. Keiser, Signal Degradation in Optical Fiber, pp. 113-115. McGraw-Hill, 2000.

Kishore kumar panda, Padmini Mishra, Anshika Shukla and Sthita pragnya Nayak, "Simulation and Performance Analysis of Dispersion Compensation Using DCF In Pre, Post and Symmetrical Arrangement For 40gbps DWDM Network", IRJET, Vol. 04, Issue: 11, -ISSN: 2395-0072, pp. 225-229, Nov 2017.

Ojuswini Arora and Kamal Kant Sharma, “A novel approach of Dispersion Compensation based on Fiber Bragg Grating”, Journal of Information and Operations Management,3,pp-46-49(2012).

K. 0. Hill, F. Bilodeau, B. Malo, T. Kitagawa, S. Thriault, D. C. Johnson, and J. Albert, "Chirped in-fiber Bragg gratings for compensation of optical-fiber dispersion”, Optics Letters, Vol. 19,pp.1314-1316,1994.

Sonam and Pulkit Berwal, M.S. Dhaka, “Optical System Design Using Fiber Bragg Grating with RZ Modulation Format", International Journal of Research in Advent Technology, Vol.2, July 2014.

U. Jadon, H. Nain, and V. Mishra, "NRZ VS RZ: Performance Analysis of SMF with Different Laser Sources at 10 Gbps,” IEEE Int. Conf. Recent Trends Electron. Inf. Commun. Technol., pp. 43- 46, 2016.

A. Hodzik, B. Konrad, K. Petemann, "Alternative modulation formats in N X 40 Gb/s WDM standard fiber RZtransmission systems", IEEE Journal of Light wave Technology, 20, No.4 ,April,2002.

T. Hoshida, O. Vassilieva, K. Yamada, S. Choudhary, R.Pecqueur, Kuwahara, "Optimal 40 Gb/s modulation. formats for spectrally efficient long-haul DWDM systems", IEEE Journal of Light wave Technology, Vol. 20, No. 12, 2002.

L. Sharan, V K Chaubey, "Design and Simulation of CSRZ Modulated 40 Gbps DWDM System in Presence of Kerr Non Linearity”, IEEE Xplore, "in press".

P.J. Winzer, R.J. Essiambre, “ Optical Modulation Formats”, proceedings of the IEEE, Vol. 94,No.5, pp. 952985, May 2006.

K. Yonenaga and S. Kuwano, "tolerant optical transmission system using duobinary transmitter and binary receiver”, Journal Of Light wave Technology, Vol. 15, No. 8, pp. 1530-1537, Aug. 1997.

Yue Zhou, Yufengshao, Zhifengwang, "Research on dispersion compensation of $40 \mathrm{~Gb} / \mathrm{s}$ optical duobinary coded transmission system" optics and photonics journal, vol 6, pp 190-195, 2016.

J. L. Walsh, - A closed set of normal orthogonal functions-, American Journal of Mathematics, 45(1):5-24, enero 1923.

V. Milosevic, V. Delic and V. Senk, - Hadamard transform application in speech scrambling,„ Proc. IEEE, vol. 1, pp. 361-364, July 1997.

Tai-Kuo Woo, - Orthogonal variable spreading codes for wideband CDMA,„IEEE Trans. Vehicular Techn., vol. 51, no. 4, pp. 700-709, July 2002. 